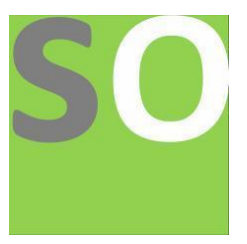

Article title: Performance Investigation of AC Servomotor Position Control using Fuzzy Logic and Observer Based Controllers

Authors: Mustefa Jibril[1], Messay Tadese[2], Eliyas Alemayehu[3]

Affiliations: School of Electrical and Computer Engineering[1], Faculty of Electrical and Computer Engineering[2] Orcid ids: 0000-0002-3165-2410[1]

Contact e-mail: mustefazinet1981@gmail.com

License information: This work has been published open access under Creative Commons Attribution License http://creativecommons.org/licenses/by/4.0/, which permits unrestricted use, distribution, and reproduction in any medium, provided the original work is properly cited. Conditions, terms of use and publishing policy can be found at https://www.scienceopen.com/.

Preprint statement: This article is a preprint and has not been peer-reviewed, under consideration and submitted to ScienceOpen Preprints for open peer review.

DOI: 10.14293/S2199-1006.1.SOR-.PPORUUL.v1

Preprint first posted online: 25 June 2020

Keywords: AC servomotor, Induction motor, Fuzzy logic, Observer based controllers 


\title{
Performance Investigation of AC Servomotor Position Control using Fuzzy Logic and Observer Based Controllers
}

\author{
Mustefa Jibril $^{1}$, Messay Tadese ${ }^{2}$, Eliyas Alemayehu Tadese ${ }^{3}$ \\ ${ }^{1}$ Msc, School of Electrical \& Computer Engineering, Dire Dawa Institute of Technology, Dire Dawa, \\ Ethiopia \\ ${ }^{2}$ Msc, School of Electrical \& Computer Engineering, Dire Dawa Institute of Technology, Dire Dawa, \\ Ethiopia \\ ${ }^{3}$ Msc, Faculty of Electrical \& Computer Engineering, Jimma Institute of Technology, Jimma, Ethiopia \\ mustefa.jibril@ddu.edu.et
}

\begin{abstract}
An AC servomotor which is mostly a two-phase induction motor with two stator field coils placed 90 electrical degrees apart used for controlling position, speed and acceleration in manufacturing industries. In this paper, a two-phase induction motor has been designed with a fuzzy logic and observer based controllers to improve the performance of the system. Comparison of the AC servomotor with the proposed controllers for tracking a step and a square desired position signal input has been done using Matlab/Simulink toolbox and a promising result obtained.
\end{abstract}

Keywords: AC servomotor, Induction motor, Fuzzy logic, Observer based controllers

\section{Introduction}

$\mathrm{AC}$ servomotor is a rotary actuator or linear actuator that lets in for specific manage of angular or linear position, velocity and acceleration. It consists of a suitable motor coupled to a sensor for role feedback. It also requires a fairly sophisticated controller, often a devoted module designed mainly to be used with servomotors. AC servomotors aren't a specific elegance of motor, despite the fact that the term servomotor is often used to consult a motor suitable for use in a closed-loop control system. AC servomotor is a closed-loop servomechanism that makes use of position feedback to control its movement and very last role. The input to its manipulate is a signal (either analogue or digital) representing the position commanded for the output shaft.

\section{Mathematical Model of the AC Servomotor}

An AC servomotor is basically a two-phase induction motor that has two stator field coils placed 90 electrical degrees apart, as shown in Figure 1.

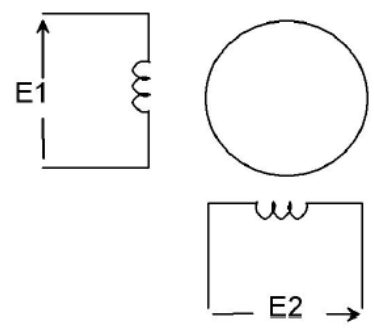


Figure 1 AC servomotor

In a two-phase motor the ac voltage E1 and E2 are equal in magnitude and separated by a phase angle of 90 degrees. A two-phase induction motor runs at a speed slightly below the synchronous speed and is essentially a constant-speed motor. The synchronous speed ns is determined by the number of poles $\mathrm{P}$ produced by the stator windings and the frequency $\mathrm{f}$ of the voltage applied to the stator windings.

When the unit is used as a servomotor, the speed must be proportional to an input voltage. The two-phase motor can be used as a servomotor by applying an ac voltage E1 of fixed amplitude to one of the motor windings. When the other voltage E2 is varied, the torque and speed are a function of this voltage. Figure 2 shows a set of torque-speed curves for various control voltages.

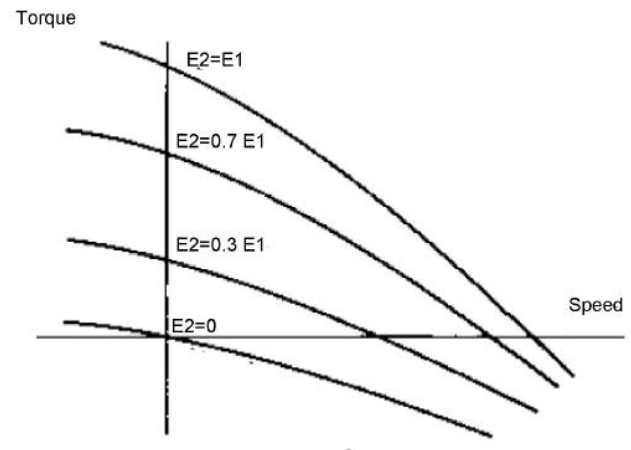

Figure 2 Torque-speed curves for various control voltages

The torque generated is a function of both the speed $\omega$ and the control-field voltage E2. In terms of partial derivatives, the torque equation is approximated by effecting a double Taylor series expansion of $T\left(E_{2}, \omega\right)$ about the origin and keeping only the linear terms:

$$
\left.\frac{\partial T}{\partial E_{2}}\right|_{\text {Origin }} E_{2}+\left.\frac{\partial T}{\partial \omega}\right|_{\text {Origin }} \omega=T\left(E_{2}, \omega\right)
$$

If the torque-speed motor curves are approximated by parallel straight lines, the partial derivative coefficients of Equation (1) are constants that can be evaluated from the graph.

Let

$$
\begin{aligned}
& \frac{\partial T}{\partial E_{2}}=K_{1} \\
& \frac{\partial T}{\partial \omega}=K_{2}
\end{aligned}
$$

For a load consisting of a moment of inertia and damping, the load torque required is 


$$
T_{L}=J \frac{d \omega}{d t}+B \omega
$$

Since the generated and load torques must be equal, Equation (1) and (3) are equated:

$$
K_{1} E_{2}+K_{2} \omega=J \frac{d \omega}{d t}+B \omega
$$

Rearranging and writing Equation (4) in terms of position $\theta$ becomes:

$$
J \frac{d^{2} \theta}{d t^{2}}+\left(B-K_{2}\right) \frac{d \theta}{d t}=K_{1} E_{2}
$$

In order for the system to be stable the coefficient $\left(B-K_{2}\right)$ must be positive. Observation of the motor characteristics shows that $\frac{\partial T}{\partial \omega}=K_{2}$ is negative; therefore, the stability requirement is satisfied. The transfer function of the AC servo motor becomes

$$
G(s)=\frac{\Theta(s)}{E_{2}(s)}=\frac{K_{1}}{J s^{2}+\left(B-K_{2}\right) s}
$$

Table 1 shows the parameters of the AC servo motor.

Table 1 System parameters

\begin{tabular}{|l|l|l|l|}
\hline No & Parameters & Symbols & Value \\
\hline 1 & Torque voltage constant. & $K_{1}$ & 54 \\
\hline 2 & Torque speed constant & $K_{2}$ & -28 \\
\hline 3 & Load moment of inertia & $J$ & $18 \frac{\text { N.m.s. }}{\mathrm{rev}}$ \\
\hline 4 & Load viscous friction & $B$ & $8 \frac{\mathrm{N} . \mathrm{m} . \mathrm{s}}{\mathrm{rev}}$ \\
\hline
\end{tabular}

Finally, the transfer function of the AC servo motor becomes

$$
G(s)=\frac{\Theta(s)}{E_{2}(s)}=\frac{3}{s^{2}+2 s}=\left(\frac{1}{s}\right)\left(\frac{3}{s+2}\right)
$$

\section{Proposed Controllers Design}

In this section, the design of the proposed controllers will be discussed.

\subsection{Fuzzy Logic Control}

Fuzzy Logic Control (FLC) or Fuzzy Linguistic Control is a knowledge primarily based control strategy that can be used 
- While both a sufficient correct and but no longer unreasonably complicated model of the plant is unavailable, or

- When a (single) specific degree of overall performance isn't significant or realistic.

FLC model design is based totally on empirically received knowledge concerning the operation of the process. This expertise, cast into linguistic, or rule-based form, is the main of the FLC system. The rule base (know-how base) gives nonlinear transformations with none built-in dynamics. The block diagram of the AC servomotor with fuzzy logic controller is shown in Figure 3 below.

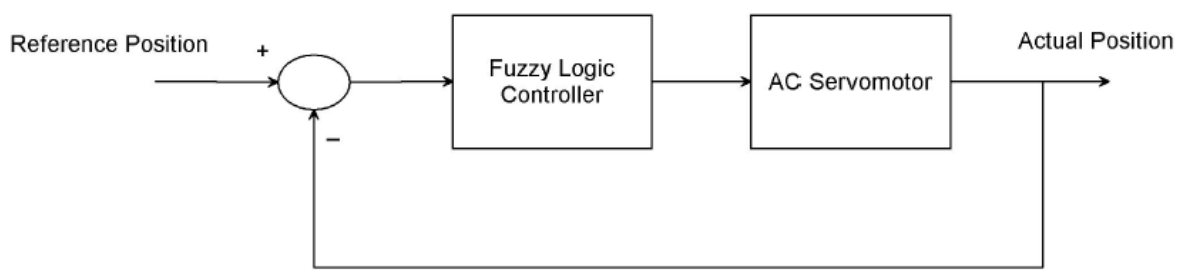

Figure 3 Block diagram of the AC servomotor with fuzzy logic controller

\subsection{Input and Output of fuzzy controller}

The error and change of error input and the output of the fuzzy logic controller is shown in Figure 4, Figure 5 and Figure 6 respectively.

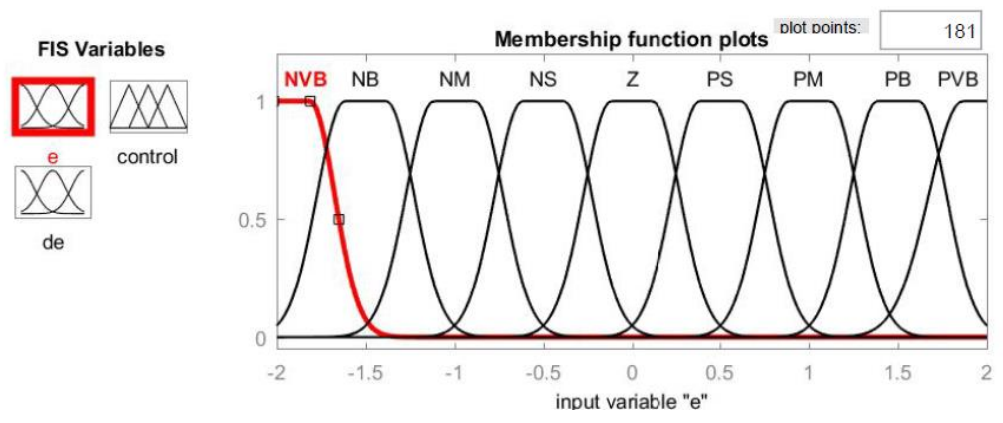

Figure 4 Error input

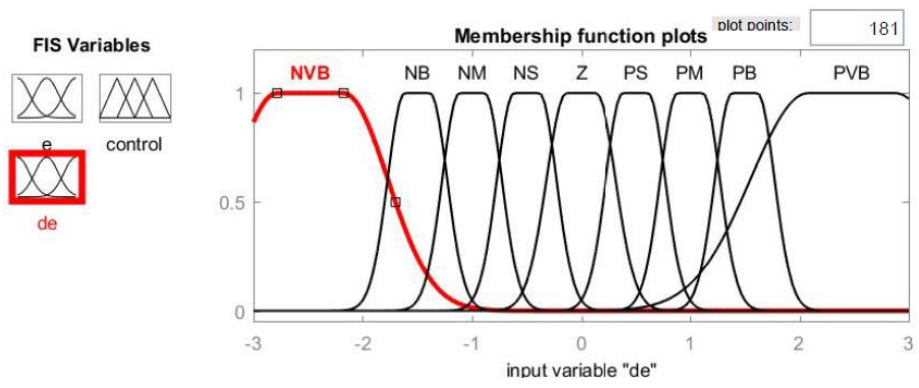

Figure 5 Change in error input 


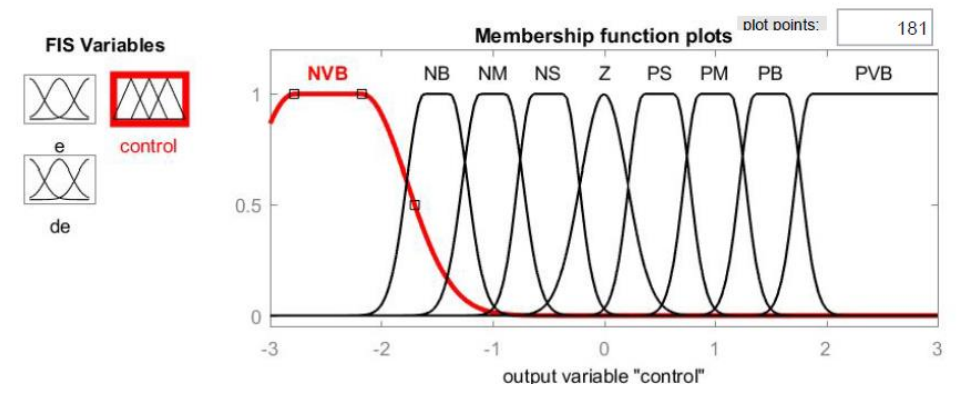

Figure 6 Output

\subsection{Observer-Based Controller Design}

The deal with the general case where only a subset of the states, or linear combinations of them, are obtained from measurements and are available to our controller. Such a guideline is referred to as the output feedback problem.

The output is of the form

$$
y=C x+D u
$$

We shall examine a class of output feedback controllers constructed in two stages:

1. Contracting an observer | a system dynamic that is driven by the inputs and the outputs of the system, and yield a deliberation of its state variables;

2. Using the estimated state instead of the actual state in a estate response scheme.

The block diagram of the AC servomotor with the observer-based controller is shown in Figure 7 bellow.

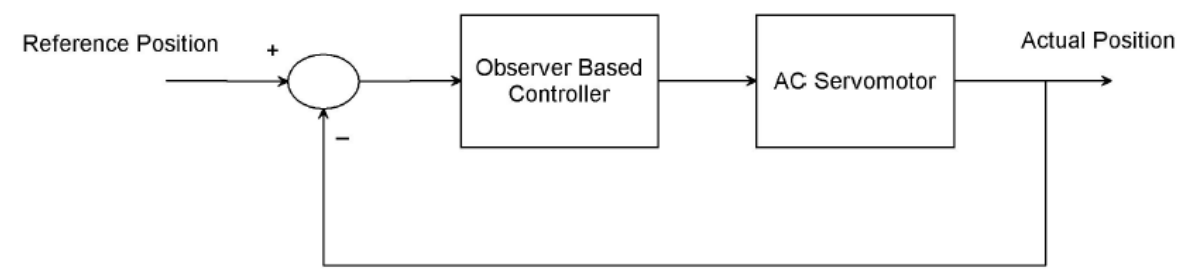

Figure 7 Block diagram of the AC servomotor with the observer-based controller

The controller Gc(s) can be further derived in the following form:

$$
G_{c}(s)=I-K(s I-A+B K+H C)^{-1} B
$$

With its state space realization

$$
G_{c}(s)=\left[\begin{array}{cc}
A-B K-H C & B \\
-K & I
\end{array}\right]
$$


The controller Gc(s) in Equation (8) is called the observer-based controller, since the structural idiot of the observer is implicitly reflected within the controller.

Where the state space model of the plant, G, the state feedback gains vector K, and the observer gain vector $H$ are then returned, respectively.

We select the weighting matrix $\mathrm{Q}$ and $\mathrm{R}$ as

$$
Q=\left(\begin{array}{ll}
3 & 0 \\
0 & 3
\end{array}\right) \text { and } R=5
$$

And we select the observer gain vector as

$$
H=\left(\begin{array}{c}
1.5 \\
-0.5
\end{array}\right)
$$

And we obtain the state feedback gain vector $\mathrm{K}$ as

$$
K=\left[\begin{array}{ll}
0.4798 & 0.7746
\end{array}\right]
$$

The observer-based controller transfer function become

$$
G_{c}(s)=\frac{0.3323 s+0.3873}{s^{2}+0.9798 s+1.555}
$$

\section{Result and Discussion}

\subsection{Comparison of the AC Servomotor with Fuzzy Logic and Observer Based Controllers} for Tracking Step Position Signal

The Simulink model of the AC servomotor with fuzzy logic and observer based controllers for tracking desired step position input signal is shown in Figure 8 below.

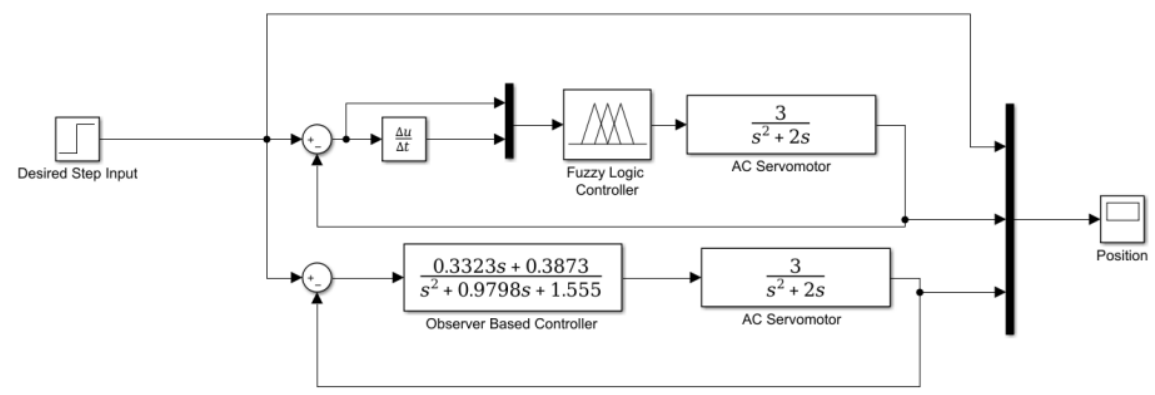

Figure 8 Simulink model of the AC servomotor with fuzzy logic and observer based controllers for tracking desired step position input signal

The comparison simulation result is shown in Figure 9 below. 


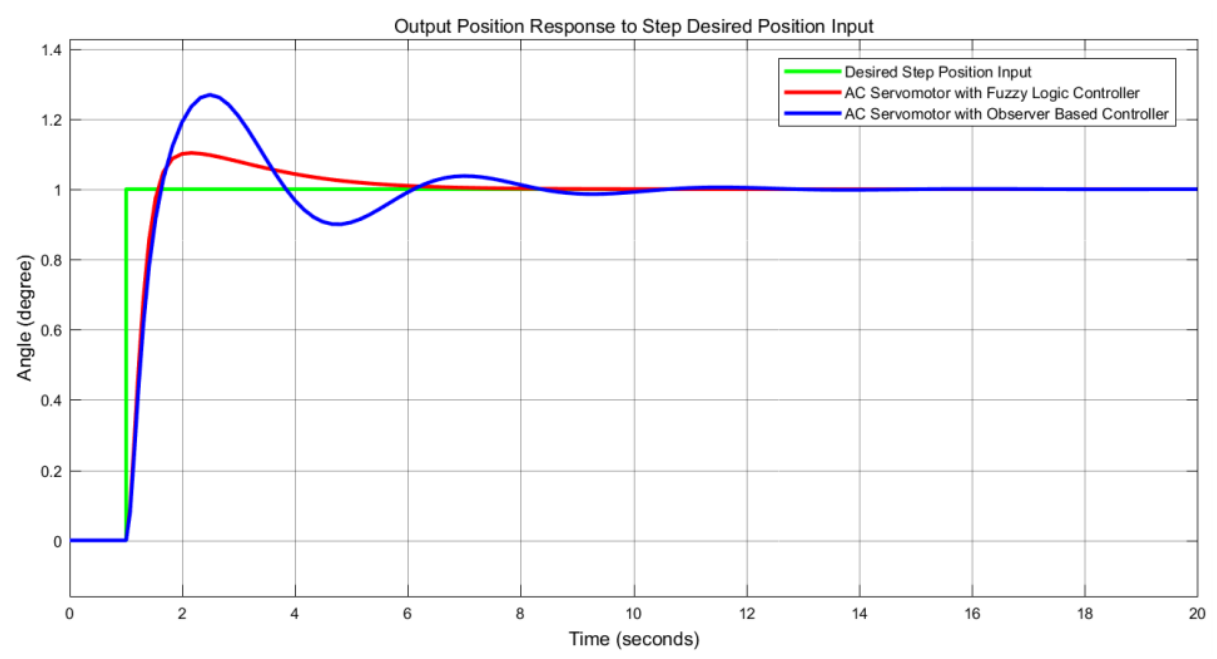

Figure 9 Step response simulation result

The data of the rise time, percentage overshoot, settling time and peak value is shown in Table 2 .

Table 2 Step response data

\begin{tabular}{|c|c|c|c|}
\hline No & Performance Data & Fuzzy Logic & Observer Based \\
\hline 1 & Rise time & $1.4 \mathrm{sec}$ & $1.4 \mathrm{sec}$ \\
\hline 2 & Per. overshoot & $12 \%$ & $29 \%$ \\
\hline 3 & Settling time & $6 \mathrm{sec}$ & $13 \mathrm{sec}$ \\
\hline 4 & Peak value & 1.12 degree & 1.29 degree \\
\hline
\end{tabular}

As Table 2 shows that the AC servomotor with fuzzy logic controller improves the settling time and the percentage overshoot better than the AC servomotor with observer based controller.

\subsection{Comparison of the AC Servomotor with Fuzzy Logic and Observer Based Controllers for Tracking Square Position Signal}

The Simulink model of the AC servomotor with fuzzy logic and observer based controllers for tracking desired square position input signal is shown in Figure 10 below.

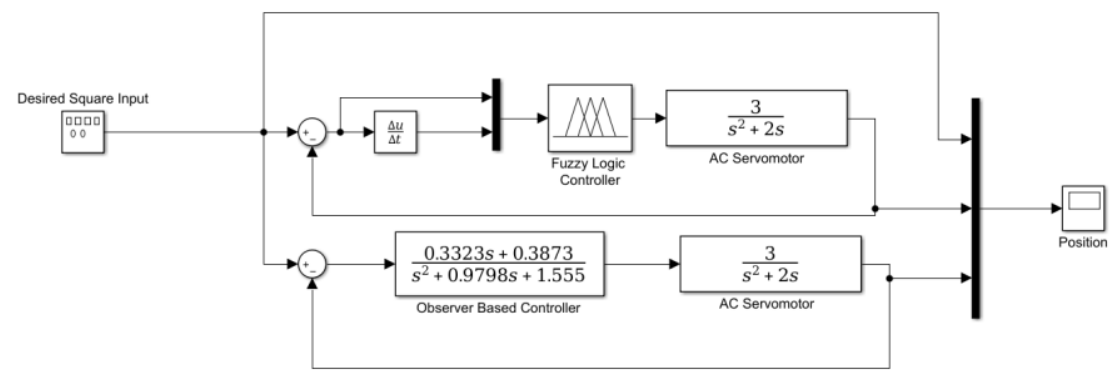

Figure 10 Simulink model of the AC servomotor with fuzzy logic and observer based controllers for tracking desired square position input signal 
The comparison simulation result is shown in Figure 11 below.

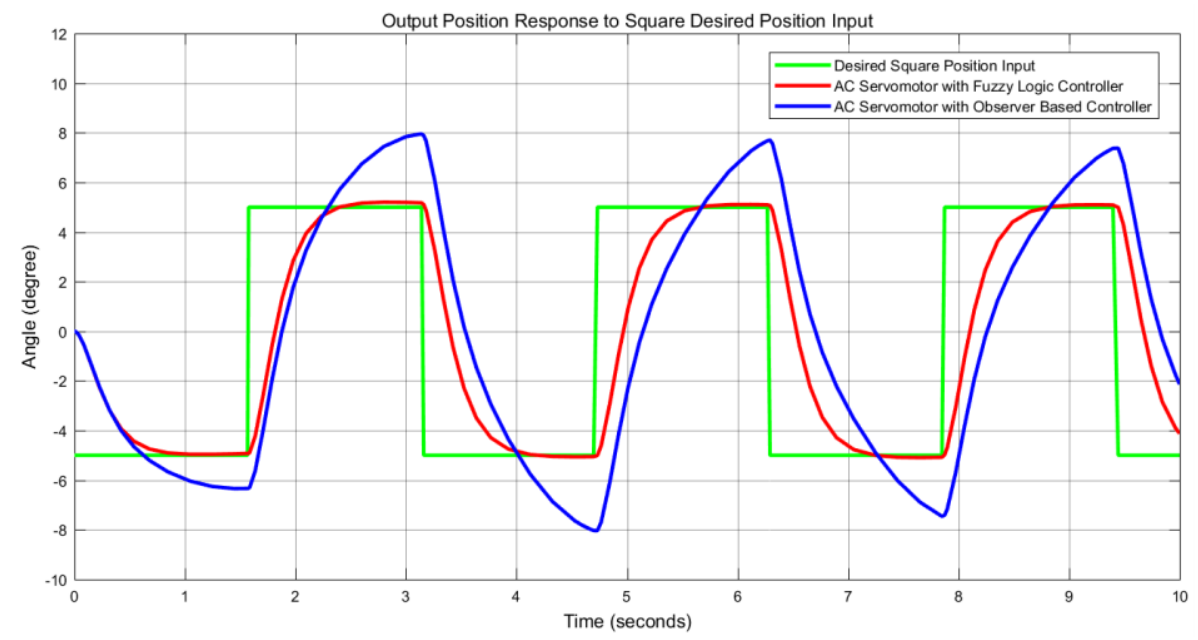

Figure 11 Square wave response simulation result

The simulation result of Figure 11 shows that the AC servomotor with fuzzy logic controller improves the settling time with 0.7 second and with zero percentage overshoot.

\section{Conclusion}

In this paper, modeling, designing and simulating of an AC servomotor with fuzzy logic and observer based controllers have been done with the help of Matlab/Simulink Toolbox successfully. A two-phase induction motor that has two stator field coils placed 90 electrical degrees apart is used as a servomotor by applying an ac voltage $\mathrm{E} 1$ of fixed amplitude to one of the motor windings and the other voltage $\mathrm{E} 2$ is varied. Comparison of the $\mathrm{AC}$ servomotor with the proposed controllers for tracking a step and a square desired position signal input has been done. The simulation result for tracking the desired step input position signal proves that the AC servomotor with fuzzy logic controller improves the settling time and the percentage overshoot while the simulation result for tracking the desired step input position signal proves that the AC servomotor with fuzzy logic controller improves the settling time with 0.7 second and with zero percentage overshoot.

\section{Reference}

[1].Rahmat et al. "Fuzzy-PI Algorithm Application to Controlling Servo Motor Position using Microcontroller AVR" Journal of Physics: Conference Series, Vol. 1517, 2020.

[2]. Bargaje S. et al. "Voltage Regulation using AC Servomotor" International Research Journal of Engineering and Technology, Vol. 06, Issue 04, pp. 4043-4045, 2019.

[3]. Oh, Hyun-Woo "A Study on Servo Motor Control in Multi Pallet System" IEMEK Journal of Embedded Systems and Applications, Vol. 14, Issue 6, pp. 339-346, 2019.

[4]. Chaoran Wang et al. "Effect of Delays on Current Loop Bandwidth in Servo Motor Control System" AIP Conference Proceedings, Vol. 2154, Issue 1, 2019.

[5]. Shimao Yu. et al. "Research on Model Based Design Method of Permanent Magnet Synchronous Motor Servo System Based on FPGA" The International Conference on Mechanical, Electric and Industrial Engineering, Vol. 1074, 2018. 
[6].Sheng-Liang Chen et al. "Synchronized Injection Molding Machine with Servomotors" AITI Advances in Technology innovation, Vol. 2, No. 2, 2017.

[7]. Ahmed S. et al. "Position Control of AC Servomotor using Internal Model Control Strategy" International Journal of Engineering Innovations and Research, Vol. 4, Issue 2, 2015.

[8].Mehmet F. et al. "AC Servo Motor Speed and Position Control using Particle Swarm Optimization (PSO)" Hittite Journal of Science and Engineering, Vol. 2, No. 2, 2015. 